\title{
The Natural Changes of Solar-Terrestrial Relations
}

\author{
G.Y. Smolkov \\ Institute of Solar-Terrestrial Physics SB RAS, 664033, Irkutsk, Russia, p/b 291 \\ Email: smolkov@iszf.irk.ru
}

\begin{abstract}
Natural changes in solar-terrestrial relations, including the global climate of the Earth, without taking into account all the factors of external influence on them, are still completely incomprehensible. In this connection, synchronous responses of the atmosphere layers of the Sun and all shells of the Earth, due to external influences on them in 1997-1998 were considered. The events and processes of these years have caused a temporary slowdown in global warming in 1998-2013.
\end{abstract}

Keywords: Solar-terrestrial relations (STR), solar activity (CA), global warming (GW).

\section{Introduction}

One of the constant properties of the variability of the natural environment on Earth is its inconstancy. It occurs at different time scales. Traditionally, the existing approaches to the diagnosis and study of STRs, their manifestations in the atmosphere and climate are very diverse, fragmented and limited. The methodology of studying their manifestations has been reduced mainly to elucidate the relationships and interrelationships of the responses of the outer shells of the Earth to external influences, up to now mostly only on CA and GCR fluxes, by analyzing the correlation relationships of the trends of the interesting indices and modeling the links between them, which attempts to explain the concepts of the disciplines of researchers. To understand the current state of relations, it is necessary to take into account their evolution in earlier times. This is not ensured by reliable data of tool registrations at the required time scales and forces the use of proxy data, which inevitably leads to uncertainty of the results of the STRs study, since the indirect data are burdened both by errors in their receipt and by errors due to the specific nature of the "vectors" of information (Smolkov, Barkin, 2016).

Relevant literature on the impact of the volatile SA on the atmosphere and climate, is vast, but much has been based on inadequate statistics and non-robust procedures. Selection of ground responses can often occur (inadvertently or otherwise) from the use of intervals of limited data and / or the choice of compared parameters. This is the main reason for the occurrence of specific problems in the study of the effect of CA on climate. The phenomena of internal climate variability are often overlooked or underestimated. There are internal fluctuations (especially associated with the oceans over a ten-day time scale), and the common mistake is to re-fit the data, thereby erroneously attributing variations to external solar origin. There are a large number of publications considering oscillations in periods close to solar cycles and / or correlations with the solar cycle with a fixed lag. The checks of some of them show that they are unlikely to be due to CA, and that they most likely reflect other natural cycles of the climate system or a harmonic mix of different perennial cycles. Even a statistically significant correlation or detection of a periodic impact does not establish a cause-and-effect relationship, neither the accepted delays, nor the phase relationships of coupled systems, including stationary oscillations. Finally, the question: Is there a realistic mechanism or series of mechanisms that could meet the requirements (be equal) of the correlation? (Lockwood, 2012).

In analyzing the astrophysical effects on the climate, the following difficulties are encountered when researchers try to ascribe climate trends to the effects of CA: the solar effect has significant uncertainties, the responses of the climatic system as a whole and the duration of the glaciers, in particular, are nonlinear, dating of the duration of fluctuations and CA have uncertainties, as well as contributions of volcanic and other influences; complex models of global circulation need to take into account all nonlinear interactions and feedback mechanisms within the climate system (de Jager C et al., 2010).

Until now, natural processes have been studied mainly monodiscriminarily: climatologists and meteorologists have studied atmospheric processes, oceanologists and hydrogeologists - the aquatic environment, 
geologists, mainly - the upper part of the earth's crust, geophysics - deep structure, physical processes in different shells of the Earth, with attempts to explain events and processes by the concepts of the disciplines listed.

The study of CA evolution, climate and tectonic activity of the Earth showed that these processes change synchronously, as if they are controlled from one center. The researchers have a natural temptation to attribute the conductor's functions to their own branch of knowledge: solar, atmospheric, tectonic processes or the effects of electromagnetic, magnetic and gravitational fields. But in this competition the solar system as a whole wins. The main causes (sources), for example, of climatic fluctuations, are outside the Earth. Contribution to the variability of the atmosphere and climate is brought not only by the previously discussed CA and GCR fluxes, but also by multifactor endogenous activity (causing energy, cyclicity, polar asymmetry, synchronism, changing the Earth's shape, geomagnetic field, etc.) and the consequences of external effects on the solar system as a whole (Smolkov, Barkin, 2016). Scientists and practitioners have not yet fully understood the role and contribution of the EAA in the STRs, however, their recording seems inevitable.

If we follow traditional views on the nature of STRs, it can be noted that the contribution of CA, which primarily relates geophysical variations, for example, to the same climate, depends heavily on the time interval due to the differential character of the STR at different time scales. It turns out that the $\mathrm{CA}$ is not the only and determining factor: in the intervals up to 25 years - the contribution of the CA is less than $2 \%$, for decades, the region of growth of the contribution of the SA, and of the order of 100 years - the contribution to $30-40 \%$ and the 1000 -year scale the average contribution of CA to the variance of temperature changes is about $20 \%$ (Nagovitsin, 2012); and on a larger time scale, the contributions of already cosmophysical factors are assumed. Consequently, in fact, only a part of climate changes can be explained by the influence of the SA (but with the establishment of their mechanisms, cyclicity, synchronism, polar asymmetry, etc.). Despite frequent attempts to search for the cosmophysical factor of external impact on the Earth (Kropotkin et al., 1963, Gorkavy et al., 1994; Dergachev, Raspopov, 2000, 2004, 2008, 2015), modern research in the Earth sciences and left unanswered questions about the causes of activity of natural processes and the observed spatial and temporal properties (Smolkov, Barkin, 2014, 2016).

The traditional restriction of the existing concepts of the variability of the natural environment and the factors that determine them led to an impressive analytical review as a result of the forced enumeration of a large number of unanswered questions and explanations, as well as the enumeration of the required additional information and data, further elucidation of the mechanisms, etc. (Gray et al, 2010). This confirms our view that the study of STRs is at the search stage, it needs to search for and take into account all the initial (external) factors that cause the variability of the natural environment, and systemic and interdisciplinary studies of them (Smolkov and Barkin, 2014, 2016).

According to several variations of global surface temperatures, instrumentally-registered, since 1850 , it has been checked: are all ten-year and multi-decadal climate variations of an astronomical nature. Registrograms derived from the orbits of the planets represent very similar power spectra. On two registers, eleven frequencies are closely correlated with a period between 5 to 100 years. Among them, large climatic fluctuations such as the "peak-hollow" with an amplitude of about 0.1 and $0.25{ }^{\circ} \mathrm{C}$, and periods of about 20 and 60 years, respectively, synchronized with the orbital periods of Jupiter and Saturn. The temperature registers also show 11- and 22-year-old solar cycles. The 9.1-year cycle is synchronized with the orbital cycles of the Moon. A phenomenological model based on these astronomical cycles can be used for a good reconstruction (recovery of character) of temperature fluctuations since 1850 and make partial forecasts for the 21st century. It has been established that at least $60 \%$ of the global warming observed since 1970 was caused by the combined effect of the above-mentioned natural climatic fluctuations. Partial prediction shows that the climate can be stabilized or cool to 2030-2040. Qualitatively discussed are possible physical mechanisms with an emphasis on the phenomenon of collective synchronization of coupled oscillators (Scafetta, 2010). Synchronization of the manifestations of STRs in the galactic time scales was also discovered (Berry, 1991, 2006).

The current state of the study of STRs, including climate, are characterized by: the unpreparedness or impossibility of explaining the evolution of the STRs without taking into account the role and contributions of all external factors of impact on the Earth and the Sun (Smolkov, Barkin, 2016), the accumulated unresolved problems and emerging complex new issues, the crisis of climatology (Watts, 2014), forced proposals and measures to overcome it, climate control (although an intrusive determinant recog- 
nizes the anthropogenic factor) and the recognition of its inability using proxy data (leading to uncertainty of the results), frequent references to natural or internal variability of the natural environment or the climate system without explaining its essence, disbelief of the IPCC (attracting dependent and helpful experts, not taking into account the physical nature of all external influences and concomitant circumstances, the inconsistency of the model litigation in the interests of developed countries' economies), postulating feedback, nonlinearity and adjustable parameters for the adjustment of the contribution of the anthropogenic factor to observations, the publication of dialogues and comments on the report of the IPCC_2013 with 6 problems, the imposition that consensus science is not a consensual discipline and its categorical avoidance (Kraig et al., 2015), the forced recognition of the non-systematic and noninterdisciplinary nature of research, the diversity of approaches to their implementation, "third force" and the role of cosmophysical impacts without assessing their contribution, mechanisms, etc. (Sidorenkov, 2009). All this is due to incomplete physical concepts of natural processes and events, climate changes, the objective imperfection of climate models, short for reliable determination of long-term climate changes (Smolkov, Barkin, 2016).

The Intergovernmental Panel on Climate Change (IPCC) notes that "There are fundamental limitations to accurately predict annual temperatures due to the chaotic nature of the climate system", but then, nevertheless, makes "predictions" with "certainty." The questionable use of global temperature is along with the problems of modeling a chaotic system. Meteorologists who simulate the weather find that their predictions become unstable in a week or two, and they have the advantage of refining their models by comparing forecasts with observations. The IPCC ignores the possibility of the effect of decreased solar activity during the last decade, the temperature anomaly (as it were) has no physical meaning (rather: it cannot be understood), models try to predict the future of a chaotic system, and there is an appeal to consensus to create a science about climate. Is it not time to admit that we do not understand the climate sufficiently well to know how to direct it. (Watts, 2014).

The international non-governmental group of experts on climate change (NIPCC) strongly rejects the requirement of "scientific consensus" for the causes and consequences of climate change (Kraig et al., 2015). In her opinion, climate is an interdisciplinary problem requiring knowledge from many areas. Very few scientists own more than one or two of these disciplines. Fundamental uncertainties arise from insufficient observational data, disagreements about how to interpret data and how to set model parameters. IPCC in the search for and dissemination of studies that justify the anthropogenic origin of global warming is not a reliable source. The NIPCC's conclusion, based on their extensive review of scientific evidence, is that any impact of the global climate on a person is within the background variability of the natural climate system and is not dangerous. The book does not explain the nature and causes of the observed natural variability of the climate and its polar asymmetry.

The international non-governmental group of experts on climate change (NIPCC) strongly rejects the requirement of "scientific consensus" for the causes and consequences of climate change (Kraig et al, 2015). In her opinion, climate is an interdisciplinary problem requiring knowledge from many areas. Very few scientists own more than one or two of these disciplines. Fundamental uncertainties arise from insufficient observational data, disagreements about how to interpret data and how to set model parameters. The IPCC, established to search for and disseminate research that has anthropogenic impact on global warming, is not a reliable source. The NIPCC's conclusion, based on their extensive review of scientific evidence, is that any global climate impact on a person is within the background variability of a natural climate system and is not dangerous. The book does not explain the nature and causes of the observed natural variability of the climate and its polar asymmetry.

Taking into account all the above, it is advisable to use the recordings of very representative synchronous responses of layers of the Sun's atmosphere (from the surface to the corona, Figures 1-3) and the Earth's shells (selectively, only Figures 4-11) to explain the "pause" or temporary slowdown of global warming in 1998-2013 (Fig. 7, 8). 


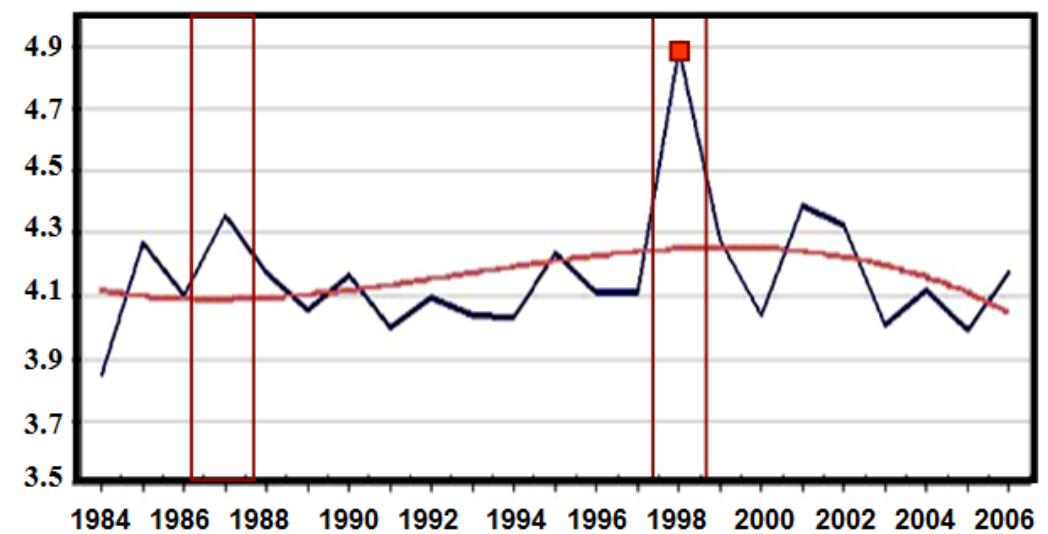

Figure 1. Spasmodic change in the mean-annual levels of solar radiation in 1998. The Monterrey, MX, solar radiation incident. July 1983 - December 2005. (1 unity $=1000 \mathrm{Kcal} / \mathrm{m} 2$, dark blue is the mean-annual, and brown is the cubic approximation in Kcal/m2)(Barkin, 2013, 2014).

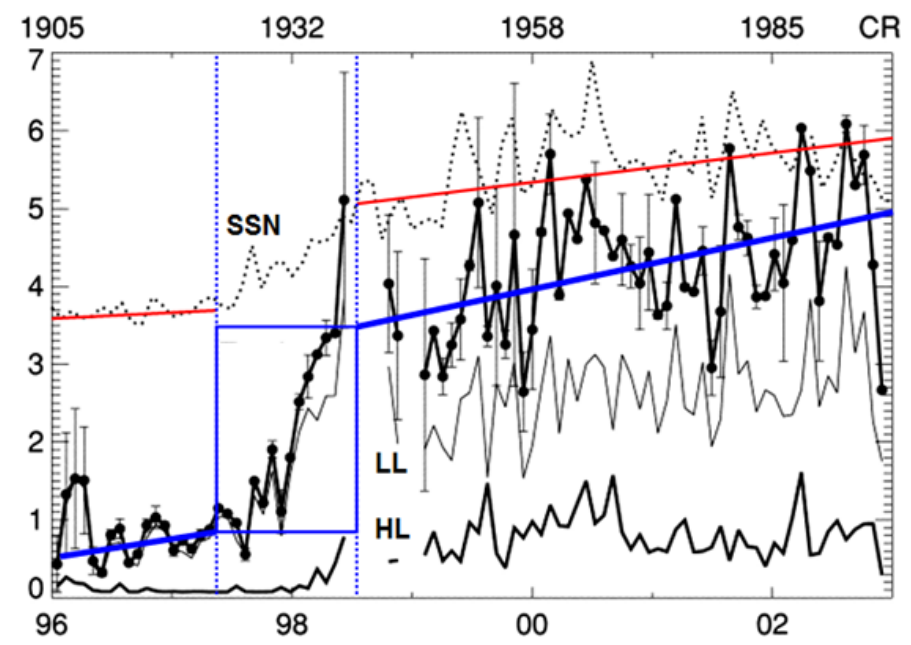

Figure 2. The spread rates of CMEs averaged over the Carrington periods according to LASCO (a thick line with dark circles) compared to the daily values of SSNs. Sinfulness for each turnover is estimated from the SOHO data. LL and HL - the behavior of the speeds of low-and high-latitude CMEs, respectively (Gopalswamy, 2003).

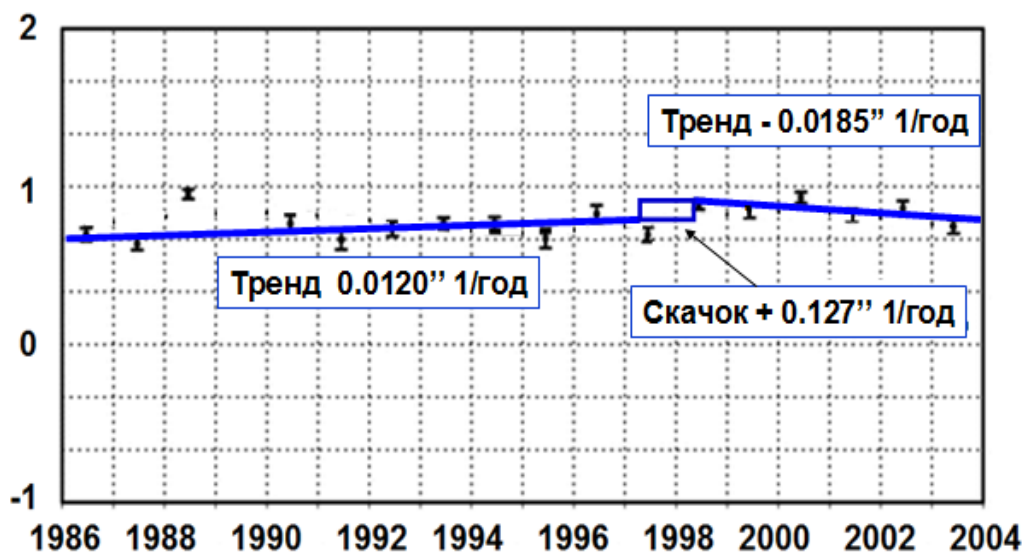

Figure 3. Linear trends of the radius of the Sun before and after the jump in radius change in 1997-1998. To +0 "187. Estimates linear trends are - 0.0083 "/ year (before the jump) and - 0.0124" / year (after the jump) (Chapman et al., 2008). 


\section{Discussion}

Synchronous events on the Sun and Earth. Exposure of the Earth and the Solar system to external influences is unambiguously confirmed by synchronous responses of all shells of the Earth and the atmosphere of the Sun, recorded by terrestrial and orbital observatories in 1997-1998 (Barkin, 2013; Smolkov, Barkin, 2016). The first official news about a part of them turned out to be the treatment of more than 300 well-known scientists from more than 85 countries around the world in 2010, with the apprehension of the Secretary-General of the United Nations and the Heads of State, together with the report of the International Geochange Committee on Global Geological Change "Geochange" registration of "spasmodic" energy changes in different layers of our planet, since the late 1990s (Khalilov, 2010). The unusual nature of the report is, first of all, the synchronism of events and the interdisciplinarity of their nature. For the first time, it was reported about simultaneous global natural changes in the Earth's shells of the cataclysmic class.

The results of the initial review of changes in the statistical and energy characteristics of natural disasters of various types of earthquakes and volcanic eruptions, tsunamis, floods, storms, hurricanes, tornadoes, forest fires, important geophysical events 1997-1998 (see below) in the framework of previous approaches were shocking (http://ru.geochange-report.org/index.php).

It became obvious that global climate changes are occurring according to the same laws as processes in the Earth's crust and deeper layers of the Earth. The elucidation of the connection between events and processes occurring in the outer and inner shells of the Earth is recognized as one of the three main directions of Earth sciences (Khain, 2009). The reasons for the difference in approaches to the study of STRs, which cause disputes about their essence so far, are their inadequate system and interdisciplinarity (Smolkov, Barkin, 2014, 2016).

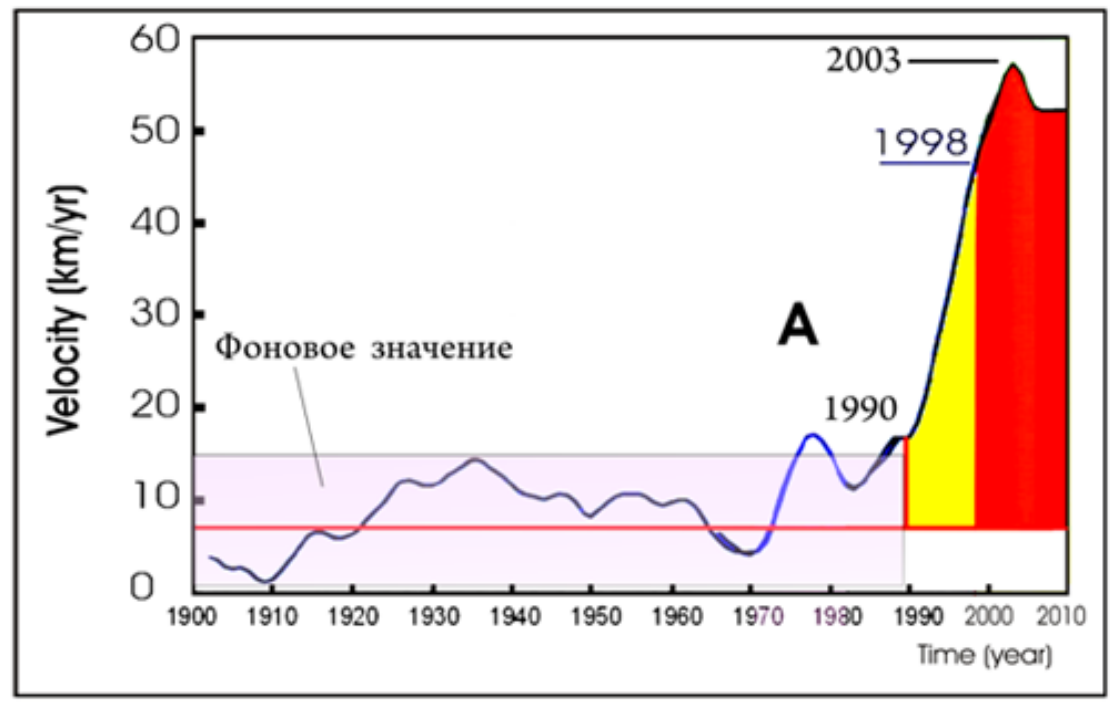

Figure 4. The convulsive increase in the speed of movement of the northern geomagnetic pole in 1998 (Olsen and Mandea, 2007) (http://geo-change.org/Pdf/Will_the_Magnetic_North_Pole.pdf) (http://onlinelibrary.wiley.com/doi/10.1029/2007EO290001/epdf) 

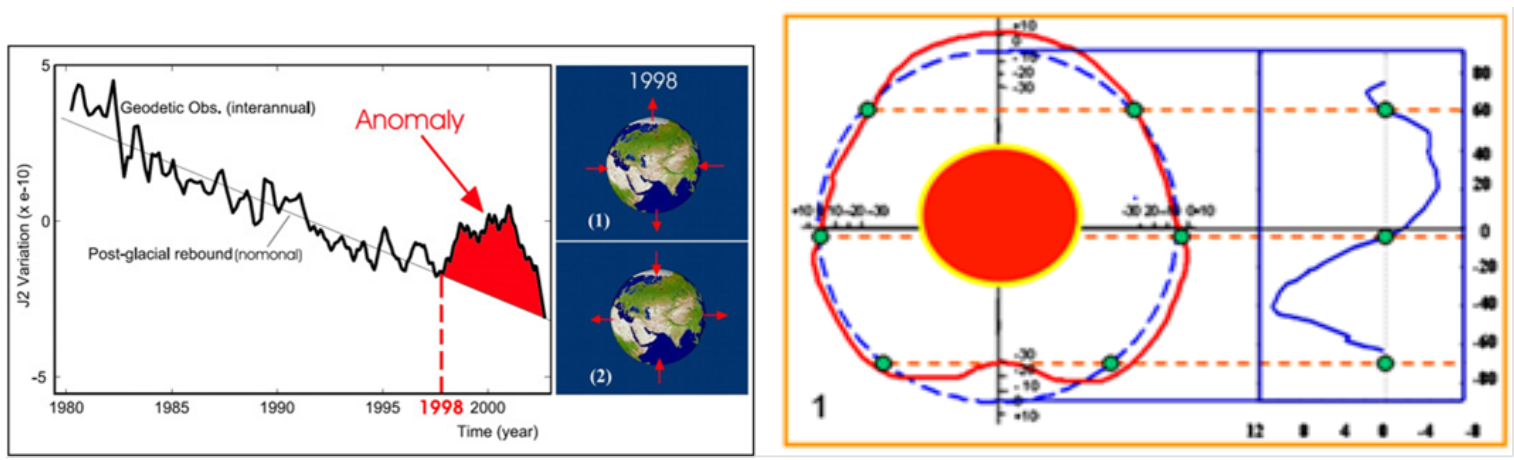

Figure 5. Change of Earth's shape in 1998. Left: NASA, using the LDS, registered in 1998 an abnormally high change in the so-called the coefficient $\mathrm{J} 2 \sim \mathrm{Re} / \mathrm{Rp}$, i.e. the shape of the Earth, the redistribution of its mass. NASA experts were confused, saying that if before 1998 the satellites recorded a steady decrease in the Earth's radius in the equator and its increase at the poles, then since 1998 this trend has changed dramatically to the opposite: the Earth began to expand in the equator and contract in the regions of the poles. It was a completely unusual leap in changing the shape of the Earth, and so far no unambiguous convincing answer about the causes of this phenomenon was found in NASA (Khalilov, 2010). (http://2012over.ru/prognoz-geochange-o-priblizhenii-globalnojjkatastrofi.html). Right: the age-old changes in the pear-shaped form of the Earth and the speed of secular variations in the lengths of latitudinal circles along orbital measurements with the manifestation of its polar asymmetry (Barkin,2013).

The Geochange report reflects changes in strong natural events: various atmospheric cataclysms, global changes in the drift velocity of magnetic fields (Fig. 4), changes in the second harmonic of Earth's geopotential J2 (indicating a change in the shape of the Earth, Fig. 5). Their parameters have begun to grow synchronically and exponentially since 1998! Since the late 1990s, the growth of statistical and energy characteristics of many natural disasters on the Earth has sharply accelerated. Over the past 20 years, the drift velocity of the North Magnetic Pole has increased by more than $500 \%$, for the first time, for the entire hundred-year period of observations, and this rate remains practically unchanged (Fig. 4). The geomagnetic field of the Earth is formed as a result of complex energy processes in the liquid core (Barkin, 1995-2009a). Consequently, if the magnetic poles moved five times faster, then in the energy at the core level, a jump occurred (Fig.6) and this energy splashed out in the late 1990s (Fig. 4-11). Its first signs were manifested in the form of an increase in the seismic (Fig. 7) and a decrease in the volcanic activity of the Earth (Fig. 8).
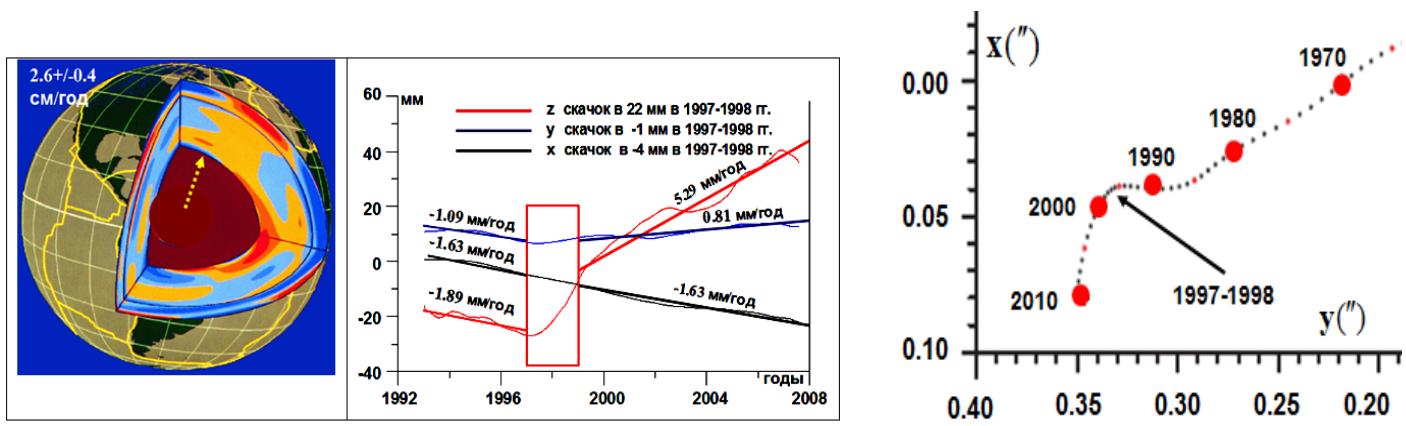

Figure 6. Earth's interior, direction of the Earth's Center of mass centennial drift, and the trajectory of its pole on the Earth's surface in 1990-2010 (left) with an $~ 90^{\circ}$ turn in 1997-1998 (middle) in direction to the Taimyr Peninsula region (right) (Zotov, Barkin, 2009). 

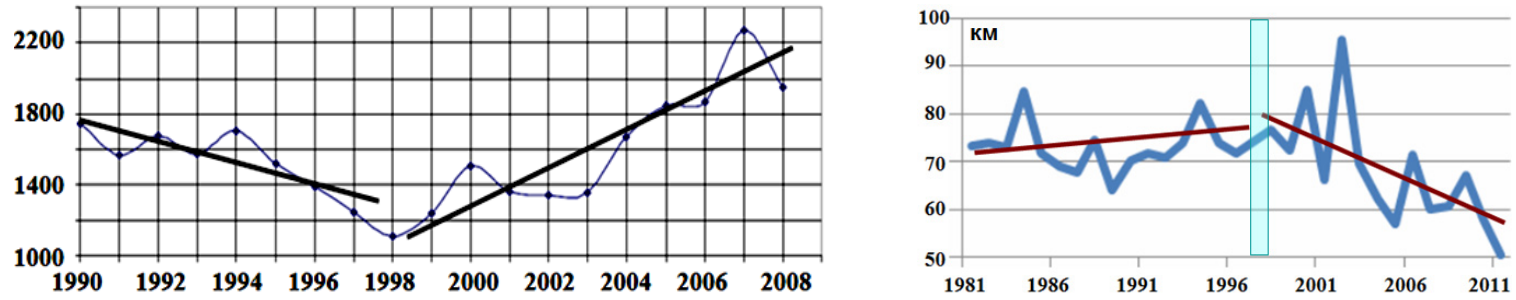

Figure 7. Change in the total number of earthquakes and strong earthquakes with a magnitude $>5$ over the past 20 years (http://earthquake.usgs.gov/earthquakes) - on the left. The abrupt change in the trends of the average annual depths of earthquake foci in 1997-1998. (http://www.novisio.com/htmlearthqt.htm) - on the right

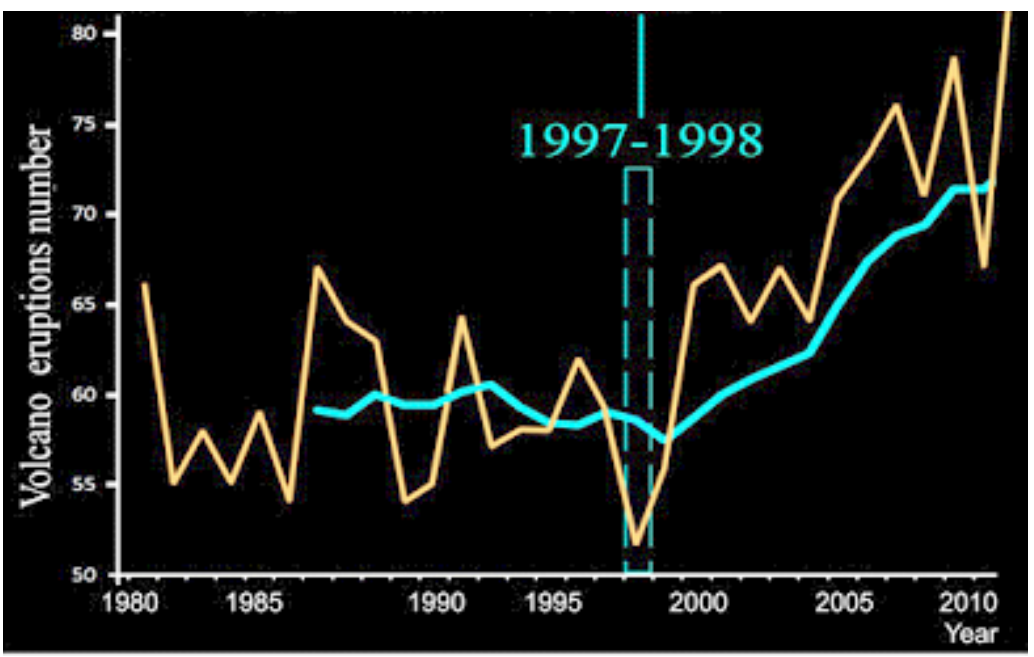

Figure 8. The graph of the number of volcanic eruptions from 1980 to 2010 . The second, hollow curve is the trend of the number of volcanic eruptions, smoothed by 11-year averages moving, the kink is the impact on the Earth in 1997-1998. (Khalilov, 2010) From external influences, not indignation, but calm?

In 1998, a sharp increase in the number of many natural disasters began on Earth (Barkin, 2009b, Figures 4-11). All of them were synchronous to events recorded on the surface of the Sun and layers of its atmosphere (Fig. 1-3).

The specificity of El Nino 1997-1998, which began to gain strength in December 1996 and was completed only in 1998, turned out to be a "phenomenon of the century" (Figure 9). In 1998, the highest the average annual air temperature for all the years of instrumental observations. Was this the result of the "phenomenal" El Niño of 1997-1998, or increasing anthropogenic influence? It is necessary to find out. For the years 1997-1998, from an area of about 75 million $\mathrm{km}^{2}$, an enormous amount of heat and water vapor was added to the atmosphere, which, as a result of the transfer by air currents, manifested itself in different regions of the Earth, in some cases - in heavy rains and catastrophic floods, and in others severe droughts. El Niño transferred 450 million megawatts $(1012 \mathrm{~W})$ to the atmosphere, which exceeds the power of volcanoes and earthquakes, with a capacity of 300,000 large nuclear power plants. The phenomenal "El Niño" ended very sharply, and already in March-April 1998, the atmosphere and the ocean in the equatorial zone began to return to normal conditions. In the years 1997-1998, El Niño was best predicted with a complex, combined ocean-atmosphere model at the European Center for MediumRange Weather Forecasts (ECMWF, UK). This model for 13-14 months "guessed" the time of the beginning of the phenomenon in the Pacific, but its model intensity as always was significantly lower than the real one. However, the disturbed state of the planetary circulation of the atmosphere, generated by El Niño, continued to exist. In 1999, the global climatic phenomenon El Niño, which manifested itself particularly strongly in 1998, was still significantly influenced by the overall climate background. In connection with this, an increase in the frequency of non-favorable short-term natural phenomena was expected: the periods of anomalously warm and cold weather, strong winds and 
snowfalls, etc. According to the calculations of the British Meteorological Administration, the total damage caused to them is about 50 billion US dollars (Semenov, 1999).
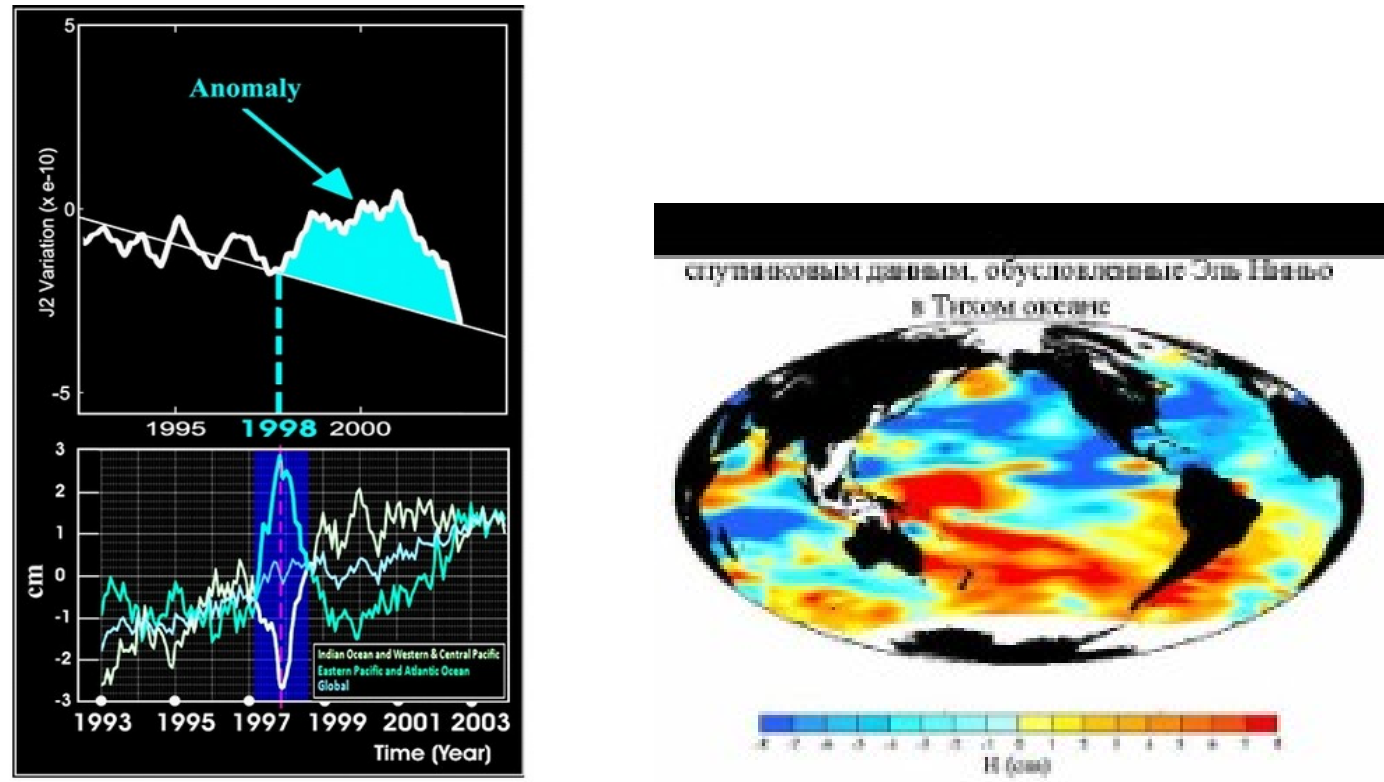

Figure 9. Left: Variations of the J2 coefficient (from above), the dynamics of ocean levels (Indian, Western and Central Pacific, Eastern Pacific and Atlantic) and a general graph of world ocean level fluctuations (below). The maximum values of ocean level variations coincide in time (from 1998) with the beginning of a sharp jump in the coefficient J2. Since 1998, the transfer of water masses has changed. The geophysical causes of the increase in the current J2 are not definite. This means large changes in the global distribution of the masses (Cox, Chao, 2002, 2003). The climatic significance of these rapid shifts in the ice and ocean masses remains the subject of research. Questions: To what extent are changes in ocean levels observed, and El Niño processes can trigger registered changes in J2? What is their reason? (Khalilov, 2010). Right: The unusual El Niño-Southern Oscillation (ENSO) phenomenon is the largest and most important signal in the interannual variability of the climate in the oceanatmosphere system, is observed regularly, every 2-7 years, the effects of ENSO are significant climatic anomalies in various regions of the globe. The specificity of El Nino 1997-1998, which began to gain strength in December 1996 and was completed only in 1998, turned out to be a "phenomenon of the century" with the development of three centers of activity (http://fb.ru/article/144430/el- nino --- chto-eto-gde-obrazuetsya-techenie-ego-napravleniefenomen-i-yavlenie-el-nino \# image428730)

The consideration of the synoptic mechanism for the formation of "anomalies" of atmospheric circulation in the lower and upper troposphere of the Pacific showed that for all the diversity of synoptic situations of the "active" class of the warm phase of ENYUK, three variants of the location of the centers of activity of the tropical atmosphere, each of which forms its scenario for the development of anomalies of the western wind. For the first time, the existence of an extended band of equatorial western winds on an isobaric surface of $500 \mathrm{hPa}$ during the periods of maximum activity of ENUK was discovered. This indicates that tropical cyclones during the warm phase that form the anomaly of the western winds are not weak and single tropical depressions, but represent well-developed vertical baricocirculation formations that arise during the most active periods of the warm phase of the El Niño phenomenon-the southern wave in whole series. Such vertical structure of the wind field above the equator is not observed anymore in any region of the tropical zone of the Earth (http://migjournal.ru/mstatute\&id=1288). This was the case in 2014 (http://science.nasa.gov/science-news/scienceat-nascal/2014/19may_elnino/).

The residual excess of the temperature balance of the Sun was registered at $0.31^{\circ}$ during the period 1990-2008 in 1999. Therefore, some connection between the warming of the Earth's surface and the evolution of the solar dynamo (de Jager et al., 2010) is not excluded. 
The consequences of synchronous events that occurred on the Sun and Earth in 1997-1998. (Figure 1-11). The "pause" or temporary slowdown in the trend of the average surface temperature from 1998 to 2013 (Fig.10), revealed at the American Geophysical Union session in 2016 on the US climate, raised questions: What happened? and What does it mean?

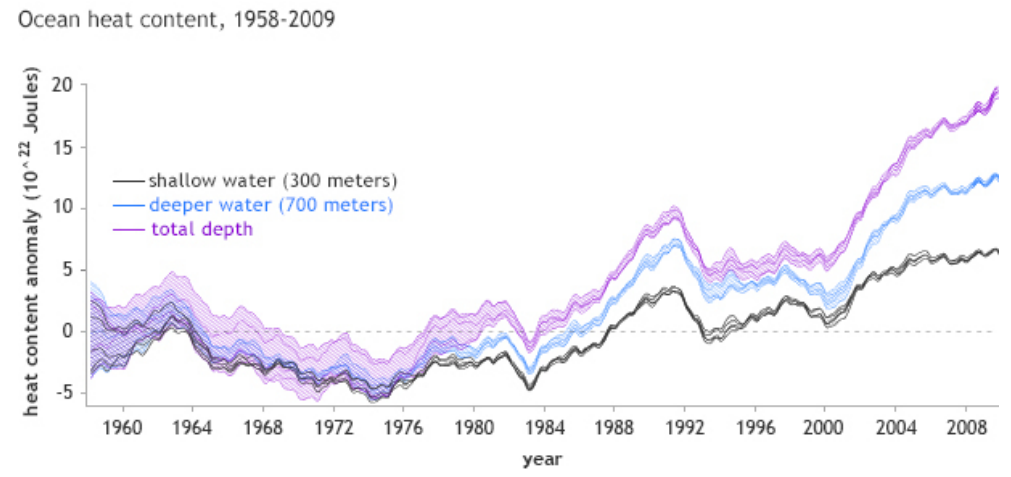

Figure 10. The appearance of a pause or temporary global warming from 1998 to 2013 . Yearly global ocean heat content compared to the 1958-65 average (dashed line at zero) for the past four decades for different layers of the ocean: from the surface to depths of 300 meters (grey) and 700 meters (blue), and total depth down to 2,000 meters (purple). Surface waters warmed more slowly (line is nearly flat since the mid-2000s) than deeper waters (steep increase). Since the core of the Argo fleet can only dive down to 2,000 meters, the amount of heat going into the deep ocean is unknown ( Balmaseda et al., 2013).

Discussion of the facts in traditional terms led the session participants mainly to: 1) The last study of the temporary slowdown in the trend of global mean surface temperature warming, noted between 1998 and 2013, attributed the phenomenon to the ocean of the Earth, absorbing the additional heat of the planet; 2) At timescales of a decade or so, the natural variability of the climate plays a big role in the speed of global surface warming (author: but references to the natural variability of the climate system without explaining its nature), but the global mean surface temperature of the Earth is still growing; 3) A deeper understanding of how heat is spreading around the world will help scientists better consider how the Earth responds to this additional heat energy (http://www.universetoday.com/132083/globalwarming-hiatus-not- good-news-planet-earth/). It is only natural that the possible reason for a "pause" or a temporary slowdown in global warming (effectively manifested even in variations in the surface temperatures of the coastal waters of the oceans, especially at low and middle latitudes) belongs to the tsunami - long and high waves, generating a powerful wave action on the entire thickness water in the ocean (Figure 11).
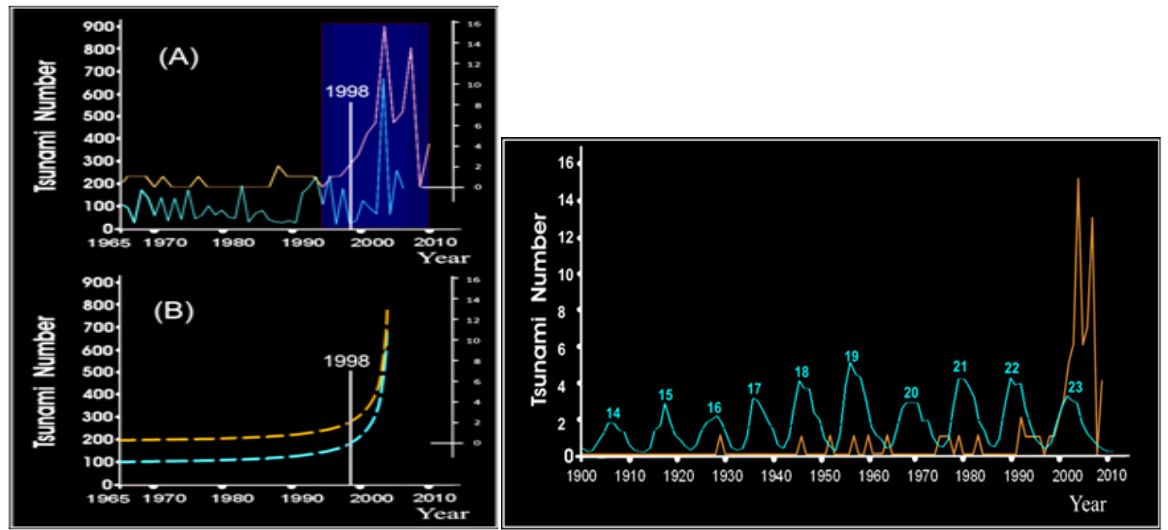

Figure11. Left: Comparison of the graph of the number of strong tsunamis (yellow) with the graph of cyclicity of solar activity (blue). As can be seen from the comparison, there is no one-to-one relationship between tsunami and solar activity, only partial - during the 16, 18, 19, 21, 22 and 23rd cycles of solar activity. With strong earthquakes, 
as is known, are closely related tsunami, which are, usually, the consequence of strong earthquakes in the aquatic environment. Right: Graphs (A) show the dynamics of annual tsunami numbers: yellow - catastrophic, blue - weak and medium. On the graphs (B) - respectively, their exponential dynamics trends. The state of the environment, which is affected by the tsunami to full depth, leads to a huge exchange of masses of ocean water. The number of tsunamis in the late 1990s grew nonlinearly, exponentially (Khalilov, 2010). A similar regional disturbance of the mixing of warm and cold layers was observed with the course of the Gulf Stream, accompanied by a change in the regional climate.

Accounting for all external factors allows explaining the temporary decrease in global warming in 1998-2013. The reason for all this is a powerful external synchronous effect on the Earth and the solar system as a whole, which occurred in 1997-1998. (Smolkov, 2017). The UN recognized its forecast of warming as erroneous, but still considers the main (http://lb.ua/news/2010/01/20/ 21015_klimatologi_oon_priznali_svoi_pr.html) anthropogenic factor. The decision of the XXI Conference on Climate (2015, Paris) does not correspond to a similar manifestation of STR. The need for systematic and interdisciplinary research of STR has not been eliminated (Smolkov, Barkin, 2014, Kraig et al, 2015).

To explain the above phenomena, it is advisable to turn to energy, mechanisms, cyclicity, polar asymmetry, synchronism, spasmodic and other forms of manifestation of STRs, presented by the author together with prof. YV Barkin at the conference "Astronomy from near space to cosmological distances" (GAI MSU, May 2015) in explaining their external causes (Smolkov, Barkin, 2016). Brief explanations are as follows.

The primary questions of the theory of natural planetary processes on the Earth are questions about the sources of energy of the EAE (endogenous activity of the Earth) and the basic mechanism of its cyclic energy excitation. The solution of this age-old problem was proposed on the basis of the mechanism of excitation of Earth's shells by other celestial bodies of the Solar System (Barkin, 2002).

The basic position of the geodynamic concept is that the planets, satellites and the Sun are shell systems according to their evolution - near the Earth: the core (solid and liquid), the mantle (plastic and hard), the lithosphere, the earth's crust, the atmosphere, which under external gravitational the action is made relative to each other by small translational and rotational movements, as well as deformation and other changes. At the same time, part of the mechanical energy is transformed into thermal energy, forming the internal thermal field of the Earth. According to the geodynamic model of the Earth, developed by prof. Barkin, based on the provisions of celestial mechanics [Barkin, 2002], there is a single mechanism that controls and directs cyclic activity of virtually all terrestrial processes - the mechanism of forced interaction, buildup of the core, mantle and other shells of the Earth and their deformations under the influence of the gravitational attraction of the Moon, the Sun and the other planets in the process of the barocentric motion of the solar system. This mechanism is universal and effectively works on many bodies of the solar system. It determines the cyclicity of geodynamic and geophysical processes in a wide variety of time scales from hours to hundreds of millions of years. When considering purely the gravitational mechanism of the STR, it is shown that this mechanism can be schematically represented as the following chain: planets - barycentric motion of the Sun - variations in the angular velocity of the Earth's rotation - variability of geophysical and climatic processes (Khlystov et al., 2012).

The external impact depends on the position of the surrounding celestial bodies, but the latter vary cyclically in different cycles of time. This means that the interactions of the shells with each other are also cyclical with a set of frequencies that are derived from the basis frequencies of the orbital motions of celestial bodies (coincide with the base frequencies or are their various combinations). It is clear that these mechanical interactions are, as it were, primordial, then generating a sequence of all possible interactions of all layers, shells, geodynamic and geophysical processes (naturally, also cyclical). The entire solar system represents the totality of celestial bodies mutually disturbing each other. The mutuality of their being in the same system, causes the synchronization of the processes occurring in the Solar system (Barkin, 2002, 2013).

According to the EAE concept (with simplifications of the expressions of the force functions of the Newtonian and gravitational interactions of celestial bodies and shells of the Earth, the assumption of the orbits of the planets as circular ones), the energy balance of the Earth and the power of the processes compose: seismic events of $3 \times 10^{10} \mathrm{~W}$, volcanic events of $10^{10} \mathrm{~W}$, thermal convection $10^{13} \mathrm{~W}$, heat flux (4.4-4.8) $\times 10^{13} \mathrm{~W}$, tides of $4 \times 10^{11} \mathrm{~W}$, dissipation due to core vibrations and visco-elastic deformations 
of the mantle $3.38 \times 10^{14} \mathrm{~W}$, total power dissipation of energy in the Earth's mantle $10^{14}-10^{15} \mathrm{~W}$ (Barkin, 2002), (upper bounds $1,45 \times 10^{16} \mathrm{Bт}$, Авсюк, 1996). The process of gravitational differentiation of terrestrial matter is the most powerful source of endogenous energy on Earth, and simultaneously it can also feed itself and the Earth's magnetic field under the influence of all surrounding celestial bodies (Velikanov, 2006). Planets can fully provide energy for all the main natural processes of the Earth (tectonic movements, including horizontal movements of lithospheric plates, uplifts and deflections of the crust, lithosphere and other layers of the Earth, the formation of compacted layers, contents of joint systems and faults, etc.) (Barkin, 2002; Sorokhtin and others, 2010). Especially interacting moving layers of the oceans and the atmosphere.

\section{Conclusion}

Proceeding from the foregoing, the phenomenon of the temporary slowdown of global warming in 19982013, the specific activity and energy of El Niño in 1997-1998, and the diversity of tropical winds in 1997-1998 in the Pacific, the residual excess heat on the Sun in 1999 - are a consequence of a powerful external impact on the Earth and the Solar system in 1997-1998 (Fig. 1-11), which caused a small additional heat to the planet, a change in the existing heat distribution and kinematics of mobile ocean water masses, redistribution of the Earth's thermal field, which led to a temporary slowdown in global warming in 1998-2013. This external impact preceded the consequences in the global warming of 19982013. Exposure to the wave character of the perturbation to the entire depth of the ocean promoted the rise of their cold masses, the temporary slowing of the global warming, and then to the accelerated warming characteristic of the oceans.

Questions: what happened? and what does this mean? marked by the US Climate Section of the American Geophysical Union proved to be natural and logical. After a powerful external impact on the Earth and the Solar system in 1997-1998 we should expect specific effects in the trends of global warming indicators, especially in the most mobile shells of the Earth: the oceans and the atmosphere. Temporal slowdown in the average surface temperature trend since 1998 to 2013 (Fig.10) are understandable when taking into account the features of the manifestation of STRs in past years.

The role and contribution of the SA in the STR shared, along with two other cosmophysical factors the GCR fluxes and the Earth's endogenous activity, caused by the mutual gravitational influences of all other celestial bodies of the Solar system in the process of its barycentric motion and even external influences on the Solar system as a whole.

Acknowledgements. The work was carried out in accordance with the Development Program of the Siberian Branch of the Russian Academy of Sciences in 2013-2018, including Earth sciences and studies of solar-terrestrial relations.

The author is grateful for the materials he borrowed from specialized Internet sites.

\section{References}

1. Avsyuk Yu.N. (1996) Tidal power and natural processes/ - M.: RAS United Earth Phys Institute, $188 \mathrm{p}$

2. Barkin Yu.V. (2013) Synchronized jumps in the processes and phenomena on the Earth, Moon and Sun in 19971998 and their single mechanism," Geology of the oceans and seas: Proc. XX Int. Sci. Conf. Marine Geology V. M.: GEOS, 21

3. Barkin Yu.V., Klige R.K. (2012) Heliocosmic gravitational influence factors on the endogenous activity of the Earth. M.: The scientific world. ISBN 978-5-91522-311-9, 46

4. Barkin Yu.V. (1995) On the motion of the Earth's center of mass due to a global change in its dynamic structure and tidal deformations // Vestnik MGU 3 Physics, Astronomy, 36, 599

5. Barkin Yu.V. (1996) On the dynamics of the inner core of the Earth // Proceedings of the State. Astronomical Institute. PC. Shternberg, vol. 65, 107.

6. Barkin Yu.V. (1999) To the explanation of the paleomigration of the Earth's pole / / Vestnik MGU 3 Physics, Astronomy 556 
7. Barkin Yu.V. (2002) Explanation of the endogenous activity of planets and satellites and the mechanism of their cyclicity / Izv. Section of Earth Sciences RANS, Moscow: VINITI, no. 9.45.

8. Barkin Yu.V. (2009a) Moons and planets: mechanism of their active life // Proceedings of International Conference"Astronomy and World Heritage: across Time and Continents" (Kazan, 19-24.08. 2009). KSU. P. 142161

9. Barkin Yu.V. (2009b) Forced vibrations of the Earth-mantle system of the Earth and their reflection in geological, geodynamic and geophysical processes // "Geology of the Seas and Oceans: Mater. XVII Int. Scientific. Conf. On marine geology". T.V., Moscow: GEOS, 210.

10. Berry B. L. (1991) Synchronous processes in the shells of the Earth and them space reasons / MSU Vestnik 5, 1, 20; (2006a) Spectrum of the solar system and models of geophysical processes 3 64; (2006b) Solar system oscillations and models of natural processes / Journal of Geodynamics 41, 133

11. de Jager C., Duhau S, van Geel B. (2010) Quantifying and specifying the solar influence on terrestrial surface temperature / / Journal of Atmospheric and Solar-Terrestrial Physics. V. 72, 926.

12. Jager C D. Solar Forcing of Climate // Surveys in Geophysics July 2012, Vol. 33, Issue 3-4, pp 445-451.

13. Dergachev VA, Raspopov OM a) Long-term processes on the Sun, determining the trend of solar radiation and surface terrestrial temperature change // Geomagnetism and aeronomy. 2000. T.40. C.9-14.

14. Dergachev V A, Raspopov O M. Long-term solar activity - controlling factor of global warming of the 20th century // Solar-terrestrial physics. Publishing house of the SB RAS. 2008.-Iss. 12, T. 2, ss. 272-275.

15. Raspopov OM, Dergachev VA et al. Interpretation of physical causes of global and regional climate responses to long-term variations in solar activity. - In the same place, ss. 276-278.

16. Gray L. J., J. Beer, M. Geller et al. (2010) Solar influences on climate // Rev. Geophys., 48, RG4001, doi:10.1029/2009RG000282

17. Gopalswamy N., Lara A., Yashiro S., Howard R.A. (2003) Coronal mass ejections and solar polarity reversal // The Astrophysical Journal, 598, L63.

18. Gorkaviy NN, Trapeznikov Yu.A., Fridman AM On the global component of the seismic process and its relationship with the observed features of the Earth's rotation // Doklady RAN. 1994. Vol. 338, No. 4. P. 525-527.

19. Lockwood M. Solar Influence on Global and Regional Climates // Observing and Modeling Earth's Energy Flows (L.Bengtssoon et al., eds). Space Siences Series of ISSI. Springer, 2012/942222. P. 171-202.

20. Khain V.E. About the main directions in modern Earth sciences // Bulletin of the Russian Academy of Sciences. 2009. T. 79, No. 1. P. 41-43.

21. Khalilov E.N. (2010) Report of the International Committee of the GEO-CHANGE \Global energetic shock on our planet since 1998" / www.climatechange2013.org. (http://ru.geochange-report.org/index.php)

22. Khlystov AI, Dolgachev VP, Domozhilova LM (2012) Barycentric motion of the Sun and its consequences for the solar system / Modern global changes in the natural environment. T.3. Factors of global change - M .: The scientific world. - 444 p., 16 p.

23. Kraig D.I., Carter R.M., Singer S.F. Why Scientists Disagree about Global Warming: The NIPCC Report on Consensus, 2015, NIPCC, 106p.

24. Kropotkin PN, Trapeznikov Yu.A. Variations in the angular velocity of the Earth's rotation, pole oscillations and drift velocity of the geomagnetic field and their possible connection with geotectonic processes // Izvestiya AN SSSR. Ser. Geol. 1963. № 14. P. 32-50.

25. Nagovitsin Yu.A. (2012) Solar activity and solar-terrestrial connections on various time scales // Abstracts of reports Vseros. Conference "Solar activity and the nature of global and regional climate change" (19-22.06.2012, Irkutsk), P.20.

26. Scafetta N. (2010) Empirical evidence for a celestial origin of the climate oscillations and its implications /J ASTPhys $\underline{7213} 951$

27. Semenov E.K. (1999) The grandiose consequences of the distant "El Niño" // Russia in the World: 1999 (Analytical Yearbook). Ans. Ed. Marfenin N.N. / Under the general editorship: Moiseeva NN, Stepanova SA. Moscow: MNEPU Publishing House. - 324 sec. -C.1-16.

28. Sidorenkov, N.S., Wilson, I., (2009) The decadal fluctuations in the Earth's rotation and in the climate characteristics. In: Soffel, M., Capitaine, N. (Eds.), Proceedings of the "Journees 2008 Systemes de reference spatiotemporels", Lohrmann-Observatorium and Observatoire de Paris, 174. 
29. Smolkov G.Ya. The reason for the failure of the global warming trend in 1998-2013 // Geomagnetism and Aeronomy, 2017 (in press).

30. Smolkov G.Ya., Barkin Yu.V. (2014) Toward systematic and interdisciplinary study of solar-terrestrial relations / Astronomicheskii tsrkular. MGU GAI. ISBN, 1.

31. Smolkov G.Ya., Barkin Yu. V. External factors of solar-terrestrial relations // Astronomical and Astrophysical Transactions, 2016, Vol. 29, Issue 4, pp. 587-606.

32. Sorokhtin OG, Chelindar J., Sorokhtin N.O. (2010) Theory of the Earth's Development: Origins, Evolution and the Tragic Future. _ M.-Izhevsk: Institute of Computer Research, SRC "Regular and chaotic dynamics", (752 s).

33. Velikanov V.E. On the nature of the Earth's magnetic field and the movement of magnetic and geographic poles / Geophysics of the XXI century: 2005. Proceedings of the VII Geophysical Readings them. V.V.Fedynsky. - M.: The scientific world, 2006.-496 p. -C.459-466.

34. Watts A. Crises in climatology / Journal of the Royal Astronomical Society of Canada, 2013, v. 108, p. 27 / http://wattsupwiththat.com/2014/02/17/crises-in-climatology/ 